Irvan Lestari, Muhammad Naharuddin Arsyad : Penggunaan Media Pembelajaran Kartu Kuartet Peristiwa dan Tokoh Sejarah Materi Sejarah Kontemporer ........

\title{
PENGGUNAAN MEDIA PEMBELAJARAN KARTU KUARTET PERISTIWA DAN TOKOH SEJARAH MATERI SEJARAH KONTEMPORER PADA MAHASISWA JURUSAN PENDIDIKAN SEJARAH DAN SOSIOLOGI DI IKIP BUDI UTOMO MALANG
}

\author{
Irvan Lestari' $^{1}$, Muhammad Naharuddin Arsyad ${ }^{2}$ \\ ${ }^{1}$ Pendidikan Sejarah dan Sosiologi, Fakultas Pendidikan Ilmu Sosial dan \\ Humaniora, IKIP Budi Utomo Malang, email: irvan_ibu@yahoo.com \\ ${ }^{2}$ Pendidikan Sejarah dan Sosiologi, Fakultas Pendidikan Ilmu Sosial dan \\ Humaniora, IKIP Budi Utomo Malang, email: arsyadtsuki@gmail.com
}

\begin{abstract}
Teaching and learning activities should not only be carried out conventionally, such as lecturers lecturing and students listening. Learning history must have variations in its implementation, the use of media can be one way so that teaching and learning activities are not monotonous. Because history is the study of the past and historical narratives demand to be explained chronologically. Thus, a quartet card containing pictures of events and historical figures that are conceptualized in accordance with historical proclamation, is expected to be able to facilitate the delivery of contemporary historical material as well as learning activities to be active. The purpose of this study was to determine the effectiveness of the use of learning media quartet cards events and historical figures. This type of research is an experimental method, with one group pretest posttest design research design. From the results of the Kolmogorov-Smirnov test using SPSS 14 it was found that the research subjects were normally distributed and based on the results of the Paired Samples Test t-test it was found that the sig value was $0,000>0.05$. While the $t-10.921$ and for ttable at a significant level $\alpha=5 \%(0.05)$ with degrees of freedom (df) $n-1$ or $45-1=44$. 2-sided testing (significance $=0.025$ ) results are obtained for ttable at 2, 01537 with a significant level of 0.025 . Obtained the results of -test <-table $(-10,921<-2,01537)$ then $\mathrm{HO}$ is rejected and Ha is accepted. So it can be concluded that the use of Learning Media Quartet Cards Events and Historical Figures Contemporary History Materials can improve the learning outcomes of students majoring in history and sociology IKIP Budi Utomo Malang.
\end{abstract}

Keywords: Quartet Card Media, Contemporary History, Learning Outcomes

\section{ABSTRAK}

Kegiatan belajar mengajar sebaiknya tidak hanya dilakukan dengan cara konvensional, seperti dosen berceramah dan mahasiswa mendengarkan. Pembelajaran sejarah harus memiliki variasi dalam pelaksanaannya, penggunaan media dapat menjadi salah satu cara agar kegiatan belajar mengajar tidak 
monoton. Karena sejarah adalah ilmu yang mempelajari masa lalu dan narasi sejarah menuntut untuk dijelaskan secara kronologis. Maka, kartu kuartet yang berisi gambar peristiwa dan tokoh sejarah yang di konsep sesuai dengan pembabakan sejarah, diharapkan mampu mempermudah penyampaian materi sejarah kontemporer sekaligus kegiatan belajar menjadi aktif. Tujuan penelitian ini adalah untuk mengetahui keefektifann penggunaan media pembelajaran kartu kuartet peristiwa dan tokoh sejarah. Jenis penelitian yang digunakan adalah metode eksperimen, dengan desain penelitian one group pretest posttest design. Dari hasil uji kolmogorov-smirnov dengan menggunakan SPSS 14 diperoleh bahwa subjek penelitian terdistribusi normal dan berdasarkan hasil uji-t Paired Samples Test diketahui bahwa nilai sig sebesar 0,000 >0,05. Sedangkan $t_{\text {hitung }}$ 10,921dan untuk $t_{\text {tabel }}$ pada taraf signifikan $\alpha=5 \%(0,05)$ dengan derajat kebebasan (df) n-1 atau 45-1 $=44$. Pengujian 2 sisi ( signifikansi $=0,025)$ hasil diperoleh untuk $t_{\text {tabel }}$ pada 2,01537 dengan taraf signifikan 0,025. Didapatkannya hasil - $t_{\text {hitung }}<-t_{\text {tabel }}(-10,921<-2,01537)$ maka H0 ditolak dan Ha diterima. Sehingga dapat disimpulkan bahwa penggunaan Media Pembelajaran Kartu Kuartet Peristiwa dan Tokoh Sejarah Materi Sejarah Kontemporer dapat meningkatkan hasil belajar mahasiswa jurusan sejarah dan sosiologi IKIP Budi Utomo Malang.

Kata Kunci: Media Kartu Kuartet, Sejarah Kontemporer, Hasil Belajar

\section{PENDAHULUAN}

Salah satu tantangan mengajar sejarah adalah membuat materi yang menceritakan tentang peristiwa masa lalu ini menjadi menarik dan disukai oleh peserta didik. Sementara ini, kesan yang sering muncul di ruang-ruang kelas terhadap pelajaran atau pun kuliah sejarah, sering dianggap cenderung monoton dalam menghadirkan narasi masa lalu. Ceramah sebagai metode yang digunakan pengampu materi, apalagi jika menjadi satu-satunya metode bisa menjadi alasan munculnya kesan tersebut. Berangkat dari keadaan demikian ini maka keberagaman metode mengajar menjadi mutlak untuk digunakan. Implementasi cara mengajar dengan menggunakan media tertentu dapat menjadi cara agar kegiatan belajar mengajar di ruang kelas menjadi lebih menarik.

Selain itu, kecenderungan di ruang kelas yang selama ini terjadi adalah pembelajaran selalu terpusat pada pengajar (guru atau dosen) sedangkan peran 
peserta didik tidak begitu dominan. Padahal peserta didik seharusnya memiliki peranan yang lebih besar karena peserta didik sebaiknya dapat menjadi subjek belajar bukan sekadar objek belajar. Pengajar dewasa ini di tengah kemajuan teknologi dituntut untuk lebih memahami peranannya, ia sudah tidak boleh lagi terlalu dominan, maka ia harus mampu menjadi fasilitator, bukan lagi satusatunya sumber pengetahuan (Jacobsen, 2009:196). Dominannya peranan pengajar tentu juga terjadi di IKIP Budi Utomo Malang. Dosen sebagai Pengampu mata kuliah memiliki tuntutan untuk dapat menghindari cara belajar yang bersifat teacher centered dan menjadikan peserta didik lebih aktif dalam kegiatan belajar. Penggunaan media belajar yang mampu membuat peserta didik lebih tertarik dengan materi ajar serta mampu membuat mereka lebih memiliki peranan dalam kegiatan belajar merupakan hal penting dan perlu dilaksanakan.

Salah satu media belajar yang dapat digunakan untuk menjelaskan materi sejarah agar lebih menarik serta membuat peserta didik lebih aktif adalah kartu kuartet. Latar belakang digunakannya media tersebut adalah adanya temuan keefektifan media pembelajaran kartu pada beberapa penelitian, diantaranya Lu'mu \& Mantasiah (2016), Na'ima (2014) yang menyatakan bahwa penggunaan media kartu kuartet dapat memotivasi siswa dan membuat siswa antusias dalam pembelajaran (82,50\%). Dari hasil penelitian Bertasari (2014) juga diperoleh hasil serupa dimana terjadi peningkatan aktivitas belajar siswa dengan rata-rata 85,48\% (Zulfikar dan Azizah, 2017:157-158).

\section{TINJAUAN PUSTAKA}

\section{A. Media Pembelajaran}

Kata media merupakan bentuk jamak dari kata medium yang berarti perantara atau pengantar (Oka, 2017:4). Secara garis besar media adalah manusia, materi, atau kejadian yang membangun kondisi yang menyebabkan siswa mampu memperoleh pengetahuan, keterampilan, atau sikap. Dalam pengertian ini guru, teman sebaya dan buku teks serta lingkungan belajar adalah media. Secara singkat media pembelajaran adalah segala sesuatu yang menyangkut software dan hardware yang dapat digunakan untuk menyampaikan isi materi ajar dari sumber pembelajaran ke peserta didik (individu atau kelompok), yang dapat merangsang pikiran, perasaan, perhatian dan minat pembelajar sehingga proses pembelajaran menjadi lebih efektif (Jalinus dan Ambiyar, 2016:2-4). 


\section{B. Klasifikasi Media Pembelajaran}

1) Media grafis adalah media visual yang menyajikan fakta, ide, atau gagasan melalui penyajian kata-kata, kalimat, angka-angka dan simbol atau gambar. Tujuannya adalah untuk memperjelas sajian ide dan mengilustrasikan fakta-fakta sehingga mudah diingat. Contohnya adalah poster, foto, film strip.

2) Media audio adalah media yang penyampaian pesannya hanya dapat diterima oleh indra pendengaran. Jenis media audio diantaranya adalah radio dan tape recorder.

3) Multimedia merupakan suatu sistem penyampaian dengan menggunakan berbagai jenis bahan belajar yang membentuk suatu unit atau paket. Contohnya adalah modul belajar yang terdiri bahan cetak, bahan audio dan bahan audio visual (Riyana, 2012:27-44).

4) Media Realita yaitu media nyata yang ada di lingkungan alam, baik digunakan dalam keadaan hidup maupun sudah diawetkan, seperti: binatang, spesimen, herbarium dan lain-lain (Duludu, 2017:19).

\section{Manfaat Media Pembelajaran}

Menurut Akbar (2013:119) setidaknya ada empat manfaat media belajar. Pertama, memperjelas penyajian informasi. Kedua, mengarahkan perhatian peserta didik sehingga menimbulkan motivasi belajar dan interaksi langsung. Ketiga, dapat mengatasi keterbatasan indra, ruang dan waktu. Keempat, dapat memberikan kesamaan pengalaman belajar pada peserta didik.

Sastrianawati (2018:9) menjelaskan jika media belajar dapat mempermudah guru/pengajar dalam menyampaikan isi materi kepada peserta didik. Karena media mampu menjadikan materi yang abstrak menjadi lebih konkret, penggunaan waktu menjadi efektif serta mendorong minat belajar dan situasi menjadi interaktif bagi pengajar dan multi-aktif bagi peserta didik.

\section{Kartu Kuartet}

Permainan kartu kuartet adalah permainan kartu yang terdiri dari sejumlah kartu bergambar dengan tema yang sudah ditentukan. Pada setiap kartu terdapat judul dan sub judul untuk menjelaskan gambar. Pada setiap kartu terdapat judul di bagian tengah atas, di bawahnya terdapat masing- 
masing dua baris kata di bagian kiri dan kanan yang merupakan sub tema. Salah satu dari empat kata tersebut mengacu kepada gambar yang berada di bawah kata tersebut yang biasanya memiliki warna lain dari keempat kata yang ada di atas gambar.

Sedangkan media belajar kartu kuartet peristiwa dan tokoh sejarah adalah media yang hampir sama dengan permainan kuartet pada umumnya. Yaitu sejenis permainan kartu bergambar dengan judul gambar ditulis pada bagian atas kartu dan judul atau tema tulisan dibuat besar dan tebal. Sedangkan di atas gambar terdapat kata-kata, dua baris di bagian kiri dan kanan. Salah satu dari empat kata tersebut mengacu pada gambar yang terdapat di bawah kata tersebut, dibuat berwarna lain dari keempat tulisan lainnya (Zulfikar dan Azizah, 2017:158-159). Hanya saja gambar, judul dan sub judul dibuat berdasarkan materi sejarah yang merujuk pada periode kontemporer dengan tujuan sebagai media belajar.

\section{E. Sejarah Kontemporer}

Sejarah merupakan cerita masa lalu yang dialami oleh manusia, penjelasan sejarah yang berasal dari kajian ilmiah telah melewati tahapantahapan dalam apa yang disebut metode historiografi. Karena kisah masa lalu itu memiliki rentang waktu yang sangat lama dan panjang maka sejarah mengenal istilah pembabakan. Salah satu bagian dari pembabakan itu adalah periode kontemporer. Sejarah kontemporer merupakan periode paling mutakhir, dimana jejak-jejak peristiwa masa lalu itu relatif dekat dengan masa kini. Kuntowijoyo (1994:24) membuat batasan periode sejarah kontemporer dimulai dari tahun 1945.

Selain periodisasi pembahasan sejarah juga mengharuskan adanya aspek kronologis. Awal dan akhir dari apa yang diulas harus jelas. Angka tahun menjadi begitu penting, periode kontemporer selain dimulai dari tahun 1945 juga dapat dibatasi sampai pada tahun 2004 dimana terjadi peristiwa politik penting sebagai simpul cerita sejarah yaitu untuk kali pertama Indonesia memilih presiden secara langsung. Rentang tahun tersebut telah mencakup beberapa peristiwa penting yang terjadi di Indonesia. Sekaligus menjelaskan perubahan dan perkembangan politik yang terjadi. Bahkan dalam rentang itu terdapat dua istilah penting yaitu Orde Baru untuk masa pemerintahan Soeharto dan Reformasi untuk pemerintahan pasca Orde Baru. 
Dengan demikian cakupan bahasan sejarah kontemporer yang digunakan dalam penelitian ini. Menyesuaikan dengan bahasan mata kulian Sejarah Kontemporer di IKIP Budi Utomo Malang yang meliputi beberapa peristiwa yang terjadi setelah proklamasi kemerdekaan. Peristiwa-peristiwa tersebut diantaranya adalah, agresi militer Belanda, pemberontakan DI/TII, peristiwa Madiun, G 30 S/PKI, berakhirnya masa Demokrasi Terpimpin, lahirnya Orde Baru dan munculnya Reformasi. Semuanya dapat menjadi sub tema dari materi ajar dan semua peristiwa sejarah tersebut memiliki keterkaitan satu sama lain. Dalam setiap bahasan sudah pasti tidak hanya membahas kejadian-kejadian masa lalu, melainkan juga menjelaskan pelaku-pelaku sejarah sebagai individu yang memilki peranan penting dalam setiap kejadian yang disebut sebagai tokoh sejarah.

\section{F. Hasil Belajar}

Sasaran dari kegiatan belajar adalah hasil belajar, secara umum pengertian dari hasil belajar adalah kemampuan yang dimiliki oleh peserta didik setelah melalui proses belajar. Dimyanti dan Mujiono (2009:250) menjelaskan hasil belajar merupakan ukuran atau tingkat keberhasilan yang dapat dicapai oleh seorang peserta didik berdasarkan pengalaman yang diperoleh setelah dilakukan evaluasi berupa tes yang biasanya diwujudkan dengan nilai atau angka-angka tertentu serta menyebabkan terjadinya perubahan kognitif, afektif dan psikomotorik. Aspek kognitif ialah yang berhubungan dengan ingatan atau pengenalan tentang pengetahuan dan pengembangan keterampilan serta kemampuan intelektual. Sedangkan aspek afektif berkaitan dengan sikap, nilai dan pengembangan apresiasi. Aspek psikomotorik berkaitan dengan keterampilan gerak anggota badan.

Mulyasa (2006) menjelaskan hasil belajar adalah prestasi belajar peserta didik secara keseluruhan yang menjadi indikator kompetensi dasar serta perubahan perilaku peserta didik. Hasil belajar dapat menjadi acuan keberhasilan proses belajar mengajar. Sehingga jika hasil yang didapatkan tidak sesuai harapan maka dapat dilakukan usaha untuk dapat meningkatkan hasil belajar dengan cara-cara tertentu yang sesuai dengan permasalahan dan kesulitan yang dialami oleh peserta didik. 


\section{METODE PENELITIAN}

Metode yang digunakan dalam penelitian ini merupakan metode eksperimen. Dengan tujuan untuk mencari pengaruh perlakuan tertentu terhadap objek penelitian yang dikendalikan (Sugiyono, 2014:72). Adapun desain penelitian yang digunakan adalah one group pre-test post-test design. Metode penelitian yang digunakan dalam penelitian ini adalah metode eksperimen. Penelitian eksperimen adalah metode penelitian yang digunakan untuk mencari pengaruh perlakuan tertentu terhadap yang lain dalam kondisi yang terkendalikan. (Sugiyono, 2014 : 72). Adapun desain penelitian yang digunakan adalah one group pre-test post-test design. Sebelum perlakuan terhadap sampel terlebih dahulu diberi pre-test (tes awal) dan diakhir pembelajaran atau sesudah perlakuan sampel diberi post-test (tes akhir). Populasi dalam penelitian ini yaitu mahasiswa angkatan 2017 sebanyak 3 kelas. Teknik pengambilan sampel yang digunakan dalam penelitian ini adalah purposive sampling. Dari teknik tersebut sampel yang terpilih adalah kelas A angkatan 2017 sebanyak 45 mahasiswa. Dan teknik pengumpulan data menggunakan teknik dokumentasi yang berupa pre-test dan post-test hasil belajar.Analisis data dilakukan menggunakan pendekatan kuantitatif. Data yang diperoleh dari nilai rata-rata hasil pre-test dan post-test untuk mengetahui perbedaan signifikansi peningkatan hasil belajar mahasiswa prodi sejarah dan sosiologi sebelum dan sesudah Penggunaan Media Pembelajaran Kartu Kuartet selanjutya dianalisis menggunakan rumus :

$$
t=\frac{\mathrm{Md}}{\sqrt{\frac{\sum x^{2} d}{N(N-1)}}}
$$

Keterangan :

$$
\begin{array}{ll}
\mathrm{t} & =\text { uji- } \mathrm{T} \\
\mathrm{Md} & =\text { Mean dari perbedaan pre-test } \text { dan post-test }\left(\mathrm{x}_{2}-\mathrm{x}_{1}\right) \\
\mathrm{xd} & =\text { deviasi masing-masing subjek }(\mathrm{d}-\mathrm{Md}) \\
\sum \mathrm{x}^{2} \mathrm{~d} & =\text { jumlah kuadrat deviasi } \\
\mathrm{N} & =\text { subjek pada sampel } \\
\text { d.b } & =\text { ditentukan dengan } \mathrm{N}-1(\text { Suharsimi, } 2013: 349-350)
\end{array}
$$


Dan dalam analisis ini, peneliti menggunakan bantuan program SPSS 14 untuk menganalisisnya yaitu dengan Uji-t (Paired Sample Test) pada taraf kepercayaan 95\% (signifikansi 0,05).

\section{HASIL DAN PEMBAHASAN}

Pada tabel 4 ini diketahui bahwa hasil perhitungan data nilai pre-test dari 45 mahasiswa yang dijadikan subjek penelitian diperoleh nilai terendah 50 dan nilai tertinggi 85. Skor rata-rata pre-test diperoleh yaitu sebesar 66,64. Sedangkan hasil perhitungan data post-test dari 45 mahasiswa yang dijadikan subjek penelitian diperoleh nilai terendah 60 dan nilai tertinggi 95. Skor rata-rata post-test diperoleh yaitu sebesar 77.00.

Tabel 4. Perolehan Nilai Pretes, dan Postes Hasil Belajar Parameter Statistik

\begin{tabular}{|l|l|l|l|l|l|}
\hline & N & Mean & $\begin{array}{l}\text { Std. } \\
\text { Deviation }\end{array}$ & Minimum & Maximum \\
\hline pre_tes & 45 & 66,6444 & 8,01180 & 50,00 & 85,00 \\
post_tes & 45 & 77,0000 & 6,77562 & 60,00 & 95,00 \\
\hline
\end{tabular}

Berdasarkan pada tabel 4 tersebut, terlihat bahwa nilai rata-rata post-test lebih besar dari nilai rata-rata pre-test $(77,00>66,64)$. Secara umum mahasiswa mengalami peningkatan hasil belajar setelah mengikuti pembelajaran yang menggunakan Media Pembelajaran Kartu Kuartet yaitu rata-rata sebesar 10,36. Dan untuk mengetahui apakah peningkatan hasil belajar tersebut terjadi secara signifikan, maka dilakukan uji perbedaan dua rata-rata (uji-t). Untuk itu, terlebih dahulu dilakukan uji normalitas data nilai pre-test dan nilai post-test. Normalitas data nilai hasil tes dalam penelitian ini adalah persyaratan yang harus dipenuhi untuk melakukan analisis inferensial dengan menggunakan teknik statistik parametrik. Hasil pengujian terhadap hasil belajar mahasiswa (baik nilai pre-test maupun post-test) dilakukan dengan menggunakan program SPSS 14. 
Tabel 5. One-Sample Kolmogorov-Smirnov Test

\begin{tabular}{|ll|l|l|}
\hline & & pre_tes & post_tes \\
\hline $\mathrm{N}$ & & 45 & 45 \\
Normal & Mean & 66,6444 & 77,0000 \\
Parameters(a,b) & Std. Deviation & 8,01180 & 6,77562 \\
Most Extreme & Absolute &, 174 &, 160 \\
Differences & Positive &, 138 &, 151 \\
& Negative &,- 174 &,- 160 \\
Kolmogorov-Smirnov Z & 1,169 & 1,073 \\
Asymp. Sig. (2-tailed) &, 130 &, 200 \\
\hline
\end{tabular}

a Test distribution is Normal.

b Calculated from data.

Hasil uji normalitas dengan menggunakan one sample kolmogorovsmirnov test terhadap nilai pre-test dan nilai post-test mahasiswa prodi sejarah dan sosiologi IKIP Budi Utomo Malang yang ditunjukkan pada tabel 5 tersebut diperoleh nilai signifikan lebih besar dari 0,05 yaitu pre-test sebesar 0,130 dan post-test sebesar 0,200 Nilai tersebut lebih besar dari taraf nyata 0,05 yakni $(0,130$ dan $0,200>0,05)$, hal ini berarti bahwa subjek penelitian berdistribusi secara normal dan syarat untuk melakukan analisis uji-t (Paired Sample Test) telah terpenuhi.

Langkah selanjutnya adalah menganalisis data nilai pre-test dan post-test yang dilakukan dengan uji-t (Paired Sample Test). Hal ini dilakukan untuk mengetahui, apakah terjadi perbedaan yang signifikan antara nilai rata-rata mahasiswa sebelum dengan sesudah mengikuti pembelajaran dengan menggunakan Media Pembelajaran Kartu Kuartet. Uji-t (Paired Sample Test) dilakukan dengan menggunakan SPSS 14 dengan taraf kepercayaan 95\% (signifikansi 0,05), hasil uji t Paired Sample Test dapat dilihat pada Tabel 6. 
Tabel 6. Paired Samples Test

\begin{tabular}{|c|c|c|c|c|c|c|c|c|}
\hline & \multicolumn{5}{|c|}{ Paired Differences } & \multirow{3}{*}{$t$} & \multirow{3}{*}{ df } & Siq. \\
\hline & \multirow[t]{2}{*}{ Mean } & \multirow[t]{2}{*}{$\begin{array}{c}\text { Std. } \\
\text { Deviation }\end{array}$} & \multirow[t]{2}{*}{$\begin{array}{l}\text { Std. } \\
\text { Error } \\
\text { Mean }\end{array}$} & \multicolumn{2}{|c|}{$\begin{array}{l}95 \% \text { Confidence } \\
\text { Interval of the } \\
\text { Difference }\end{array}$} & & & $\begin{array}{c}(2- \\
\text { tailed) }\end{array}$ \\
\hline & & & & Lower & Upper & & & \\
\hline $\begin{array}{c}\text { Pair } 1 \text { pre_- } \\
\text { tes - } \\
\text { post } \\
\text { tes }\end{array}$ & $-10,35556$ & 6,36094 & 94823, & $-12,26659$ & $-8,44452$ & $-10,921$ & 44 & ,000 \\
\hline
\end{tabular}

Berdasarkan hasil uji-t Paired Samples Test diketahui bahwa nilai sig sebesar 0,000 > 0,05 maka disimpulkan bahwa $\mathrm{H} 0$ ditolak dan Ha diterima. sedangkan $t_{\text {thitung }}$ diperoleh sebesar -10,921 dan untuk tabel diperoleh dengan cara $\alpha=5 \% / 2$ $=2,5 \%$ (untuk uji 2 sisi) dengan derajat kebebasan (df) n-1 atau 45-1 = 44. Pengujian 2 sisi ( signifikansi $=0,025$ ) hasil diperoleh untuk $t_{\text {tabel }}$ pada 2,01537 dengan taraf signifikan 0,025 .

Perolehan dari hasil thitung $<-t_{\text {tabel }}(-10,921<-2,01537)$ maka H0 ditolak dan Ha diterima. $T_{\text {hitung }}$ bernilai negatif berarti nilai rata-rata pre-test lebih rendah dari nilai rata-rata post-test. Sehingga berdasarkan uraian tersebut dapat diartikan penggunaan Media Pembelajaran Kartu Kuartet. dapat meningkatkan hasil belajar mahasiswa prodi sejarah dan sosiologi IKIP Budi Utomo Malang.

\section{PENUTUP}

\section{Simpulan}

Agar kegiatan belajar mengajar sejarah di ruang kelas tidak monoton dan terjebak pada pembelajaran yang terpusat pada pengajar. Maka penggunaan media belajar kartu kuartet dapat menjadi alternatif agar peserta didik mampu memiliki peranan yang lebih besar, sehingga tidak hanya sekadar sebagai objek belajar melainkan dapat menjadi subjek belajar. Diharapkan dengan adanya media maka materi sejarah dapat disajikan dengan lebih menarik serta mampu menumbuhkan rasa ketertarikan peserta didik pada kisah dan tokoh sejarah.

Media pembelajaran kartu kuartet memiliki kelebihan dan keunggulan sebagaimana dijelaskan di atas. Maka penggunaannya dapat diterapkan oleh 
pengajar sebagai usaha untuk menumbuhkan ketertarikan akan pelajaran sejarah dan mampu meningkatkan prestasi sebagai hasil belajar peserta didik.

\section{Saran}

Pengembangan media sebagai upaya untuk menjadikan kegiatan belajar mengajar di ruang-ruang kelas menjadi efektif perlu dilakukan. Namun, pada satu sisi hal tersebut perlu dikaji untuk memperoleh gambaran yang lebih luas tentang kelebihan dan kelemahan yang ada. Dewasa ini di tengah perkembangan teknologi dan informasi yang semakin cepat dan masif maka inovasi dalam teknologi pendidikan adalah hal juga harus ikut berkembang. Tujuannya tidak lain adalah agar dunia pendidikan tidak ketinggalan oleh perkembangan zaman tetapi mampu mengikuti dengan baik.

\section{DAFTAR PUSTAKA}

Arsyad, Azhar. 2014. Media Pengajaran. Jakarta: Rajawali Pers.

Duludu, A.T.A Ummyssalam. 2017. Bahan Ajar Kurikulum Bahan dan Media Pembelajaran PLS. Yogyakarta: Deepublish.

Hardjasaputra, A.S. 2008. Pengantar Ilmu Sejarah. Bandung: Workshop Penelitian dan Pengembangan Kebudayaan.

Hernawan, A.H., dkk. 2007. Media Pembelajaran Sekolah Dasar. Bandung: UPI Press.

Jacobsen. 2009. Methods for Teaching. Yogyakarta: Pustaka Pelajar.

Jalinus, Nirwadi. dan Ambiyar. 2012. Media dan Sumber Pembelajaran. Jakarta Kementrian Agama Republik Indonesia.

Kuntowijoyo. 2014. Metodologi Sejarah. Yogyakarta: PT. Tiara Wacana.

Mulyasa, E. 2006. Menjadi guru profesional: menciptakan pembelajaran kreatif dan menyenangkan. Bandung: Remaja Rosdakarya.

Munadi, Yudhi. 2008. Media Pembelajaran. Jakarta: Gaung Persada.

Oka, Gde Putu Arya.2017. Media dan Multimedia Pembelajaran. Yogyakarta:

Deepublish.

Purwanto. 2013. Evaluasi Hasil Belajar. Yogyakarta: Pustaka Belajar.

Riyana, Cepi. 2013. Media Pembelajaran. Jakarta: Direktorat Jenderal Pendidikan Islam Rosdakarya.

Sanjaya, W. 2006. Strategi Pembelajaran. Jakarta: Kencana Pernada Media. Sastrianawati. 2018. Media dan Sumber Belajar. Yogyakarta: Deepublish. 
Sugiyono. 2014. Metode Penelitian Pendidikan Pendekatan Kuantitatif, Kualitatif dan $R \& D$. Bandung: Alfabeta.

Susanto, A, 2003. Teori Belajar dan Pembelajaran di Sekolah Dasar. Jakarta: Kencana Prenada Media Group.

Zulfikar dan Laelah Aziza. 2017. Keefektifan Penggunaan Media Pembelajaran

Kartu Kuartet dalam Pembelajaran Keterampilan Berbicara Bahasa Jerman Siswa Kelas Xi Ma Negeri 1 Makassar. Eralingua: Jurnal Pendidikan Bahasa Asing dan Sastra Volume 1 No.2 Agustus. 